\title{
Glyn E. Jones (Ed): Bostwick's plastic and reconstructive breast surgery
}

\author{
QMP, St. Louis, 2010, 1,800 pages, 5,000 illustrations, 4 DVDs, \$395.00 USD, \\ ISBN: 978-1-57626-233-7
}

\section{Ian Jackson}

Received: 9 March 2010 /Accepted: 9 March 2010/Published online: 6 April 2010

(C) Springer-Verlag 2010

This is the third edition of a wonderful book initially edited by John Bostwick. On my first visit to the USA, I started my tour in Atlanta and there I met the great Dr. Jurkiewicz, which, of course, was a very considerable event! I was, however, very much impressed by a young resident-John Bostwick - who was just beginning his career. Over the years, we became very good friends. One of the worst events in my life was when his wife, Jane called me about his death.

This new edition of his book has been expanded. It has been produced in two volumes and is edited by Glyn Jones. There are dedications by Foad Nahai to John and a foreword and preface by Rod Hester and Glyn Jones. Reading these is a very sad experience - they are a tribute to a wonderful person and a great surgeon.

The book consists of 22 chapters and there are 24 contributors - 11 from Europe and 13 from the USA. This is a galaxy of stars - everyone is a winner. The 22 chapters cover all aspects of this intriguing area. There are very exciting chapters which are at the cutting edge: multimodal imaging, fat grafting, cohesive gel implants, microsurgical flap reconstruction, conservation in tumor resections, aesthetic problems, and surgery after massive weight loss. I believe that it is because of John that everyone has tried their very best to make everything just a little bit better!

It is difficult to imagine that there can be or will be any competition to this masterpiece apart from new concepts in the very distant future. Every imaginable breast condition-be it aesthetic or neoplastic - is discussed in depth. It was wonderful to see a chapter on fat grafting presented by Gino Rigotti, Syndey Coleman, and others. The results presented are excellent and, for many of us, give a look into the future. This also applies to the presentation of microsurgical reconstruction by Glyn Jones and Peter Neligan. As mentioned above, however, every one of these 22 chapters is worth reading and absorbing the information, which they contain.

Congratulations need to be given to Karen Berger and her staff. This is a wonderful production-beautifully presented; the photography and artwork are superb, and there is a first-class arrangement of illustrations. I cannot imagine a breast surgeon or trainee who will not want to have this great book. I also congratulate everyone who played a part in producing this two-volume work, which will aid surgeons but, most importantly, will help our patients to achieve excellent long-term results in what can be devastating problems.
I. Jackson $(\bowtie)$

Institute for Craniofacial and Reconstructive Surgery,

Southfield, MI, USA

e-mail: eurjplastsurg@juno.com 